\title{
PENGARUH KOMPETENSI DAN LINGKUNGAN KERJA TERHADAP KINERJA PEGAWAI MELALUI MOTIVASI SEBAGAI VARIABEL INTERVENING DI DINAS PENDIDIKAN DAN KEBUDAYAAN KOTA LUBUKLINGGAU
}

\author{
Irma Idayati $^{1}$, Surajiyo ${ }^{2}$, Marvia Hazalena ${ }^{3}$ \\ ${ }^{1,2,3}$ Program Studi Manajemen, Universitas Bina Insan Lubuklinggau \\ E-mail : ${ }^{1}$ irmaidayati@ univbinainsan.ac.id, ${ }^{2}$ surajiyo@ univbinainsan.ac.id, \\ 3.marvia.hazalena@gmail.com
}

\begin{abstract}
ABSTRACK
This study entitled The Effect of Competence and Work Environment on Employee Performance through Motivation as an Intervening Variable in the Education and Culture Office of the City of Lubuklinggau. The method used in this study using a questionnaire and observation. Testing the first hypothesis, namely Variable Competence (X1) on Motivation (Z) "shows that $t$ count produces a coefficient of 16.347. With a sample size of 58 found $d f=58$ (58-2) at a significant level of 0.05, the critical value of t table is 1.672. with these results it can be said that competence has a significant effect on motivation because tcount (16.347)> t table (1.672). The second hypothesis testing is that it can be said that the work environment has a significant influence on motivation because tcount (10.038)> t table (1.672). Third Hypothesis testing can be said that competence has a significant effect on employee performance because tcount (10.412)> $t$ table ( 1.672). The fourth hypothesis testing can be said that the work environment has a significant influence on employee performance because tcount (14.897)> t table (1.672). " and testing the fifth hypothesis, it is found that the value of fcount obtained is 152.197> F table $=3.16$ and the simultaneous significant level of sig $F$ is $0.000 \mathrm{~b}$. This shows that competence and work environment have a significant influence on employee performance $(Y)$.
\end{abstract}

Keywords : Competence, Work Environment, Motivation, Employee Performance

\begin{abstract}
ABSTRAK
Penelitian ini berjudul Pengaruh Kompetensi dan Lingkungan Kerja terhadap Kinerja Pegawai melalui Motivasi sebagai Variabel Intervening di Dinas Pendidikan dan Kebudayaan Kota Lubuklinggau. Metode yang digunakan dalam penelitian ini menggunakan kuesioner dan observasi. Pengujian hipotesis pertama yaitu Variabel Kompetensi $\left(\mathrm{X}_{1}\right)$ terhadap Motivasi $(\mathrm{Z})$ menunjukan $t_{\text {hitung }}$ menghasilkan koefisien sebesar 16,347. Dengan jumlah sampel 58 ditemukan $\mathrm{df}=58$ (58-2) Pada taraf Signifikan sebesar 0,05 nilai Kritis $t_{\text {tabel }}$ sebesar 1,672. dengan hasil ini dapat dikatakan bahwa Kompetensi memiliki Pengaruh yang Signifikan terhadap Motivasi karena $\mathrm{t}_{\text {hitung }}(16,347)>\mathrm{t}_{\text {tabel }}(1,672)$. Pengujian Hipotesis yang kedua yaitu dapat dikatakan bahwa Lingkungan Kerja memiliki Pengaruh yang signifikan terhadap Motivasi karena $t_{\text {hitung }}(10,038)>t$ tabel $(1,672)$.Pengujian Hipotesis Ketiga dapat dikatakan bahwa Kompetensi memiliki Pengaruh yang Signifikan terhadap Kinerja Pegawai karena $t_{\text {hitung }}(10,412)>t_{\text {tabel }}(1,672)$.Pengujian Hipotesis yang Keempat dapat dikatakan bahwa Lingkungan Kerja memiliki Pengaruh yang Signifikan terhadap Kinerja pegawai karena $t_{\text {hitung }}(14,897)>t_{\text {tabel }}(1,672)$. dan pengujian Hipotesis kelima didapat bahwa nilai $f_{\text {hitung }}$ yang diperoleh adalah sebesar 152,197> $F_{\text {tabel }}=3,16$ dan tingkat Signifikan secara serentak sig $\mathrm{F}$ adalah $0,000^{\mathrm{b}}$. Hal ini menunjukan bahwa Kompetensi dan Lingkungan Kerja memiliki Pengaruh yang Signifikan terhadap Kinerja Pegawai (Y).

Kata kunci : Kompetensi, Pengawasan, Produktivitas Kerja
\end{abstract}




\section{PENDAHULUAN}

Motivasi yang ada pada setiap orang tidaklah sama. Untuk itu diperlukan Pengetahuan tentang pengertian dan Hakikat Motivasi, serta kemampuan teknik menciptakan situasi, sehingga menimbulkan Motivasi/dorongan bagi seseorang untuk berbuat atau berperilaku sesuai dengan yang dikehendaki oleh individu lain (Organisasi).[2]

Selain Motivasi, Kompetensi juga sangat berpengaruh terhadap Kinerja Pegawai guna mewujudkan Visi Misi Organisasi tempat bekerja. Kompetensi adalah suatu kemampuan untuk melaksanakan atau melakukan suatu pekerjaan atau tugas yang dilandasi atas keterampilan dan pengetahuan serta didukung oleh sikap kerja yang dituntut oleh pekerjaan tersebut. [2]

Selain Motivasi dan Kompetensi, Lingkungan Kerja merupakan bagian dari Lingkungan Internal dalam Organisasi.[3] Lingkungan kerja sebagai tempat dan unsur dinamis yang ada disekitar seseorang bekerja. Lingkungan Kerja bukan hanya menyangkut lingkungan Fisik tempat kerja, tetapi juga menyangkut unsur-unsur psikis yang terjadi di dalam.

Berdasarkan Observasi awal yang berkaitan dengan Kompetensi Pegawai yang ada di Dinas Pendidikan dan Kebudayaan Kota Lubuklinggau diantaranya adalah belum optimalnya keterampilan dan Pengetahuan Pegawai dalam melaksanakan tugas memberikan dampak terhadap Kinerja Pegawai.

Selain dari Kompetensi faktor Lingkungan Kerja juga sangat berpengaruh terhadap Kinerja Pegawai karena lingkungan di Dinas Pendidikan dan Kebudayaan Kota Lubuklinggau kondisi lingkungan fisik yang kurang nyaman dan tata ruang kerja yang belum rapi dan tidak beraturan.

Sementara itu Observasi yang menyangkut dengan Motivasi Kerja terdapat persoalan yaitu masih kurangnya Apresiasi dan Pujian dari Pimpinan baik secara langsung maupun tidak langsung yang diberikan kepada para Pegawai dan masalah selanjutnya menyangkut tentang Kinerja Pegawai di Dinas Pendidikan dan Kebudayaan Kota Lubuklinggau yaitu masih belum Optimalnya hasil kerja yang dilakukan oleh Pegawai di Dinas Pendidikan dan Kebudayaan Kota Lubuklinggau untuk menyelesaikan pekerjaan.

\section{TINJAUAN PUSTAKA}

\subsection{Kinerja}

Kinerja adalah hasil yang dicapai dari apa yang diinginkan oleh Organisasi.[1]

““'Kinerja adalah Pendekatan Strategis dan terpadu untuk menyampaikan sukses berkelanjutan pada Organisasi dengan memperbaiki Kinerja Pegawai yang bekerja di dalamnya dan dengan mengembangkan kemampuan tim dan Kontributor individu."[4]"

\subsection{Motivasi}

Motivasi adalah Proses yang menyebabkan intensitas, arah, dan usaha terus-menerus individu menuju pencapaian tujuan.[2]

Motivasi merupakan serangkaian proses yang membangkitkan, mengarahkan, dan menjaga perilaku manusia menuju pada pencapain tujuan.[2]

\subsection{Kompetensi}

Kompetensi merupakan landasan dasar karakteristik orang dan mengindikasikan cara berprilaku atau berpikir,menyamakan situasi,dan mendukung untuk periode waktu cukup lama.[2]

"Kompetensi merupakan dimensi Perilaku yang berada dibelakang Kinerja kompeten. Sering dinamakan Kompetensi Perilaku karena dimaksudkan untuk menjelaskan bagaimana orang berperilaku ketika mereka menjalankan perannya dengan baik."'[2] 


\subsection{Lingkungan Kerja}

"Lingkungan Kerja bukan hanya berpengaruh terhadap semangat dan kegairahan Kerja dalam pelaksanaan tugas, Lingkungan Kerja yang baik dapat merangsang orang bekerja dengan baik, pengaruhnya lebih jau besar, sebaliknya Lingkungan Kerja yang kurang baik bukan hanya berpengaruh terhadap semangat dan kegairahan Kerja Pegawai, mungkin akan membawa dampak buruk terhadap Perusahaan maupun pekerja itu sendiri."'[3]

"Lingkungan Kerja merupakan Lingkungan Internal yang mewakili faktorfaktor dalam Organisasi yang menciptakan Kultur dan Lingkungan sosial dimana aktivitas-aktivitas pencapaian tujuan berlangsung."[3]

\subsection{Penelitian Terdahulu}

1. Pengaruh Motivasi dan Kepuasan Kerja Terhadap Kinerja Karyawan Koperasi di Denpasar. Populasi data yang dikumpulkan dalam penilitian adalah seluruh account officer yang berjumlah 130 orang dari 39 koperasi yang dijadikan obyek penelitian. Tehnik sampling yang digunakan adalah tehnik Proportionate Stratified Random Sampling Hasil uji Convergent Validity menunjukkan bahwa seluruh indikator pada masing-masing variabel memiliki loading factor lebih dari 0.50 sampai 0.6 dianggap cukup memadai. Ukuran refleksif individual dikatakan tinggi jika berkorelasi lebih dari 0.70 dengan variabel yang diukur.

2. Pengaruh Kompetensi Karyawan dan Lingkungan Kerja Terhadap Kinerja Karyawan Melalui Motivasi Kerja Sebagai Variabel Intervening. Hasil penelitian menunjukkan bahwa Kompetensi Pegawai dan Lingkungan Kerja tidak berpengaruh langsung terhadap Kinerja Pegawai tetapi hasilnya menunjukkan bahwa terdapat pengaruh setelah diuji dengan variabel intervensi motivasi kerja. Pengujian Hipotesis menunjukkan bahwa Motivasi Kerja berpengaruh terhadap Kinerja Karyawan. Hal tersebut dibuktikan dengan nilai thitung $>$ ttabel $(4.241>1,96)$ dengan nilai sig $0.000(\mathrm{p}<5 \%)$.

3. The Influence of Training, Competence, and Motivasi on Employees Performance of Workers Social Security Agency in Banten Province, Indonesia. The research was designed in a quantitative descriptive method with multivariate analysis involving 110 people as the sample. The results of this study conclude the coefficient of determination $\left(R^{2}\right)$ of performance variable by 0.4085 is explained by competences, training, and motivation with $0.36,0.28$, and 0.213 , respectively. Hence, the results of this research can be a consideration in the efforts to enhance the employee performance

\section{METODOLOGI PENELITIAN}

\subsection{Desain Penelitian}

Peneliti melakukan observasi di tempat penelitian untuk mengamati fenomenafenomena yang ada. Setelah melakukan observasi, Peneliti membuat kerangka pemikiran yang berisikan variabel bebas dan variabel terikat yang akan diteliti. Kemudian peneliti membuat hipotesis atau dugaan hasil sementara untuk membuat rumusan masalah yang akan dibuat. Lalu berikutnya, peneliti menetapkan tujuan-tujuan yang ingin dicapai dari penelitian yang akan dilakukan. Serta dilanjutkan membuat atau menyusun rencana jadwal kapan waktu dilaksanankanya penelitian.

\subsection{Jenis Penelitian}

Dalam penelitian ini peneliti menggunakan jenis penelitian Kuantitatif 


\subsection{Populasi dan Sampel}

\section{Populasi}

Dalam penelitian ini populasi terdiri dari seluruh pegawai yang ada di Dinas Pendidikan dan Kebudayaan Kota Lubuklingau berjumlah 58 orang

\section{Sampel}

Karena jumlah populasinya 58 orang maka populasi di dalam penelitian ini dijadikan sampel semuanya. Maka penelitian ini menggunakan metode sampel jenuh, yaitu seluruh populasi menjadi sampel dalam penelitian ini.

\subsection{Teknik Pengumpulan Data}

Teknik pengumpulan data dalam penelitian ini adalah dengan melakukan observasi, dokumentasi, dan kuisioner yang berupa angket.

\subsection{Uji Asumsi Klasik}

1. Uji Normalitas

Pengujian Normalitas yang umum digunakan adalah Teknik Kolmogorof Smirnov. Kriteria pengujian Normalitas menurut Versi ini, jika nilai $\mathrm{p}$ Value Sig $>0,05$. Nilai $p$ Value Sig merupakan nilai perhitungan hasil pengujian normalitas.

2. Uji Linieritas

Dengan menggunakan Test for Linearity dengan taraf signifikansi 0,05, dua variabel dikatakan mempunyai hubungan yang linear bila nilai signifikansi pada Linearity $<0,05$, dan jika signifikansi pada Deviation from Linearity $>0,05$, maka kedua variabel berhubungan secara linear.

\subsection{Teknis Analisis Data}

1. Uji Regresi Linier Sederhana

$$
\hat{\mathrm{Y}}=a+b . X_{1}
$$

2. Uji Koefisien Korelasi

$$
\begin{aligned}
& r_{x y} \\
& \sqrt{\left[n \sum x 1^{2}-\left(\sum x 1\right)^{2} \cdot\left(n \sum y^{2}-\sum y^{2}\right)\right.}
\end{aligned}
$$

3. Uji t (Uji Parsial)

$$
t=\frac{r \sqrt{n-2}}{\sqrt{1-r^{2}}}
$$

4. Uji Regresi Linier Berganda

$$
Y=a+b . X_{1}+b . X_{2}
$$

5. Uji Koefisien Determinasi

$$
\begin{aligned}
& \boldsymbol{R x y} \\
& =\frac{n\left(\sum X i Y i\right)-\left(\sum X 2\right) \cdot\left(\sum Y 2\right)}{\sqrt{\left\{n \cdot \sum X^{2}-\left(\sum X i\right)^{2}\right\}} \cdot\left\{n \cdot \sum Y i^{2}-\left(\sum Y i^{2}\right)\right\}}
\end{aligned}
$$

6. Uji F (Simultan)

$$
F_{h}=\frac{R^{2} / k}{\left(1-R^{2}\right) /(n-k-1)}
$$

7. Statistik Intervening

Dalam penelitian ini Motivasi (Z) sebagai Variabel Intervening/ penyela antara Variabel Kompetensi $\left(\mathrm{X}_{1}\right)$, Lingkungan Kerja $\left(\mathrm{X}_{2}\right)$ tidak langsung mempengaruhi berubahnya Variabel Kinerja (Y). Untuk menguji pengaruh

\begin{tabular}{|c|c|c|c|c|c|}
\hline \multicolumn{6}{|c|}{ ANOVA $^{a}$} \\
\hline Model & $\begin{array}{c}\text { Sum of } \\
\text { Squares }\end{array}$ & $\mathrm{df}$ & $\begin{array}{l}\text { Mean } \\
\text { Square }\end{array}$ & $\mathrm{F}$ & Sig. \\
\hline 1 Regression & 359.171 & 2 & 179.586 & $\begin{array}{r}152 \\
197\end{array}$ & $.000^{\mathrm{b}}$ \\
\hline Residual & 64.898 & 55 & 1.180 & & \\
\hline Total & 424.069 & 57 & & & \\
\hline
\end{tabular}
variabel intervening digunakan metode analisis jalur (Path Analysis).

\section{HASIL DAN PEMBAHASAN \\ 4.1 Hasil Penelitian}

\section{Uji F (Simultan)}

Tabel 1

Uji F (Simultan)

a. Dependent Variable: KINERJA

b. Predictors: (Constant), LINGKUNGAN KERJA, KOMPETENSI

Sumber : Hasil Olahan dari Data SPSS 22, 2020

Nilai $F_{\text {hitung }}$ sebesar 152,197 dengan menggunakan tingkat keyakinan 95\%, a = $5 \%$ dan df $2(\mathrm{n}-\mathrm{k} 1)=58-2-1=55$ (n adalah jumlah data). dengan demikian hasil diperoleh untuk $F_{\text {hitung }}$ pada tingkat 55 adalah 
3,16. Maka Kriteria Kinerja adalah $F_{\text {hitung }}$ $152,197>\mathrm{F}_{\text {tabel }} 3,16$ sehingga Ho ditolak dan Ha diterima yang berarti terdapat pengaruh Simultan antara Kompetensi dan Lingkungan Kerja terhadap Kinerja Pegawai di Dinas Pendidikan dan Kebudayaan Kota Lubuklinggau.

\section{Intervening}

Tabel 2

\section{Koefisien Jalur Model I}

\begin{tabular}{|l|c|r|r|r|}
\multicolumn{5}{c|}{ Model Summary } \\
\hline Model & $\mathrm{R}$ & $\begin{array}{c}\mathrm{R} \\
\text { Square }\end{array}$ & $\begin{array}{c}\text { Adjusted } \\
\text { R Square }\end{array}$ & $\begin{array}{c}\text { Std. Error of } \\
\text { the Estimate }\end{array}$ \\
\hline 1 & $.847^{\mathrm{a}}$ & .718 & .707 & 1.476 \\
\hline
\end{tabular}

a. Predictors: (Constant), MOTIVASI, KOMPETENSI

Sumber : Hasil Olahan dari Data SPSS 22, 2020

Nilai koefisien determinasi sebesar $\mathrm{R}^{2}=0,718$ hal ini menunjukan Variabel Kompetensi $\left(\mathrm{X}_{1}\right)$ terhadap Kinerja (Y) dengan Motivasi (Z) sebagai Variabel intervening sebesar 0,718 atau $71,8 \%$ dan setelah disesuaikan nilai sisanya sebesar $28,2 \%$ dipengaruhi oleh Variabel lain yang tidak dimasukan dalam Penelitian ini. Sementara itu nilai e1 dapat dicari dengan rumus el $=\sqrt{ }(1-0,718)=0,531$

Tabel 3

Koefisien Jalur Model II

Model Summary

\begin{tabular}{|l|c|r|r|r|}
\hline Model & \multicolumn{1}{|c|}{$\mathrm{R}$} & $\begin{array}{c}\mathrm{R} \\
\text { Square }\end{array}$ & $\begin{array}{l}\text { Adjusted } \\
\text { R Square }\end{array}$ & $\begin{array}{r}\text { Std. Error of } \\
\text { the Estimate }\end{array}$ \\
\hline 1 & $.917^{\mathrm{a}}$ & .840 & .835 & 1.109 \\
\hline
\end{tabular}

a. Predictors: (Constant), MOTIVASI, LINGKUNGAN KERJA

Sumber : Hasil Olahan dari Data SPSS 22, 2020

Nilai koefisien determinasi sebesar $\mathrm{R}^{2}=0,840$ hal ini menunjukan variabel Lingkungan Kerja $\left(\mathrm{X}_{2}\right)$ terhadap Kinerja $(\mathrm{Y})$ dengan Motivasi (Z) sebagai Variabel Intervening sebesar 0,840 atau $84,0 \%$ dan setelah disesuaikan nilai sisanya sebesar $16 \%$ dipengaruhi oleh Variabel lain yang tidak dimasukan dalam penelitian ini. Sementara itu nilai e2 dapat dicari dengan rumus e1 = $\sqrt{ }(1-0,840)=0,4$

\subsection{Pembahasan}

\section{Pengaruh Kompetensi terhadap Motivasi}

Berdasarkan uji $\mathrm{t}$ dapat dijelaskan bahwa $t_{\text {hitung }}$ menghasilkan koefisien sebesar 16,347. dengan jumlah sampel 58 ditemukan $(\mathrm{df})=\mathrm{n}-\mathrm{k}=58-2(\mathrm{n}$ adalah banyaknya resoponden ) dan pada taraf signifikan sebesar 0,05 dengan demikian hasil diperoleh untuk $t_{\text {tabel }}$ pada tingkat 56 adalah sebesar 1,672. dengan hal ini dapat dikatakan bahwa Kompetensi memiliki Pengaruh yang Signifikan terhadap Motivasi karena $\mathrm{t}_{\text {hitung }}$ $(16,347)>t_{\text {tabel }}(1,672)$.

Hal ini berarti bahwa secara Parsial Variabel Kompetensi memiliki pengaruh yang Signifikan terhadap Motivasi di Dinas Pendidikan dan Kebudayaan Kota Lubuklinggau.

\section{Pengaruh Lingkungan Kerja Terhadap Motivasi}

Berdasarkan uji t dapat dijelaskan bahwa $\mathrm{t}$ hitung menghasilkan koefisien sebesar 10,038. dengan jumlah sampel 58 dirumus $(\mathrm{df})=\mathrm{n}-\mathrm{k}=58-2 \quad(\mathrm{n}$ adalah banyaknya resoponden) dan pada taraf signifikan sebesar 0,05 dengan demikian hasil diperoleh untuk $t_{\text {tabel }}$ pada tingkat 56 adalah sebesar 1,672. dengan hal ini dapat dikatakan bahwa Lingkungan Kerja memiliki Pengaruh yang Signifikan terhadap Motivasi karena $t_{\text {hitung }}(10,038)>t_{\text {tabel }}(1,672)$.

Hal ini berarti bahwa secara Parsial Variabel Lingkungan Kerja memiliki pengaruh yang Signifikan terhadap Motivasi di Dinas Pendidikan dan Kebudayaan Kota Lubuklinggau. 
3. Pengaruh Kompetensi terhadap Kinerja Pegawai

Berdasarkan uji t dapat dijelaskan bahwa $t_{\text {hitung }}$ menghasilkan koefisien sebesar 10,412. dengan jumlah Sampel 58 ditemukan $(\mathrm{df})=\mathrm{n}-\mathrm{k}=58-2(\mathrm{n}$ adalah banyaknya resoponden) dan pada taraf Signifikan sebesar 0,05 dengan demikian hasil diperoleh untuk $t_{\text {tabel }}$ pada tingkat 56 adalah sebesar 1,672. dengan hal ini dapat dikatakan bahwa Kompetensi memiliki Pengaruh yang Signifikan terhadap Kinerja karena thitung $(10,412)>t_{\text {tabel }}(1,672)$.

Hal ini berarti bahwa secara Parsial Variabel kompetensi memiliki pengaruh yang Signifikan terhadap Kinerja Pegawai Dinas Pendidikan dan Kebudayaan Kota Lubuklinggau.

\section{Pengaruh Lingkungan Kerja Terhadap Kinerja Pegawai}

Berdasarkan uji t dapat dijelaskan bahwa $t_{\text {hitung }}$ menghasilkan koefisien sebesar 14,897. dengan jumlah sampel 58 ditemukan $(\mathrm{df})=\mathrm{n}-\mathrm{k}=58-2(\mathrm{n}$ adalah banyaknya resoponden ) dan pada taraf Signifikan sebesar 0,05 dengan demikian hasil diperoleh untuk $t_{\text {tabel }}$ pada tingkat 56 adalah sebesar 1,672. dengan hal ini dapat dikatakan bahwa Lingkungan kerja memiliki pengaruh yang Signifikan terhadap Kinerja karena $\mathrm{t}_{\text {hitung }}(14,897)>\mathrm{t}_{\text {tabel }}(1,672)$.

Hal ini berarti bahwa secara Parsial Variabel Lingkungan kerja memiliki pengaruh yang Signifikan terhadap Kinerja Pegawai Dinas Pendidikan dan Kebudayaan Kota Lubuklinggau.

\section{Pengaruh Motivasi Terhadap Kinerja Pegawai}

Berdasarkan uji t dapat dijelaskan bahwa $t_{\text {hitung }}$ menghasilkan koefisien sebesar 11,529. dengan jumlah sampel 58 dengan rumus $(\mathrm{df})=\mathrm{n}-\mathrm{k}=58-2(\mathrm{n}$ adalah banyaknya resoponden ) dan pada taraf Signifikan sebesar 0,05 dengan demikian hasil diperoleh untuk $t_{\text {tabel }}$ pada tingkat 56 adalah sebesar 1,672. bahwa Motivasi memiliki pengaruh yang Signifikan terhadap Kinerja karena $t_{\text {hitung }}(11,529)>\mathrm{t}$ tabel $(1,672)$.

Hal ini berarti bahwa secara Parsial Variabel Motivasi memiliki pengaruh yang Signifikan terhadap Kinerja Pegawai Dinas Pendidikan dan Kebudayaan Kota Lubuklinggau.

\section{Pengaruh Kompetensi dan Lingkungan Kerja Terhadap Kinerja Pegawai}

Berdasarkan dari hasil perhitungan nilai $f$, diperoleh nilai $f_{\text {hitung }}$ sebesar 152,197 dengan menggunakan tingkat keyakinan $95 \% \mathrm{a}=5 \%$ dan df $2(\mathrm{n}-\mathrm{k}-1)=58-2-1=55(\mathrm{n}$ adalah jumlah data). dengan demikian hasil diperoleh untuk $\mathrm{F}_{\text {tabelpada tingkat } 55 \text { adalah }}$ 3,16 sehingga Ho ditolak dan Ha diterima yang berarti terdapat pengaruh secara Simultan antara Kompetensi dan Lingkungan Kerja terhadap Kinerja Pegawai di Dinas Pendidikan dan Kebudayaan Kota Lubuklinggau.

\section{Pengaruh Kompetensi terhadap Kinerja Pegawai melalui Motivasi sebagai Variabel Intervening}

Berdasarkan hasil koefisien jalur model I diperoleh nilai Koefisien Determinasi sebesar $\mathrm{R}^{2}=0,718$ hal ini menunjukan Variabel Kompetensi $\left(\mathrm{X}_{1}\right)$ terhadap Kinerja (Y) melalui Motivasi sebagai Variabel Intervening sebesar 0,718atau $71,8 \%$ dan setelah disesuaikan nilai sebesar $28,2 \%$ dipengaruhi oleh Variabel lain yang tidak dimasukan dalam penelitian ini.

Berdasarkan dari hasil perhitungan nilai beta diketahui pengaruh langsung yang diberikan Kompetensi (X1) terhadap Kinerja (Y) sebesar 0,285. Sedangkan Pengaruh tidak langsung Kompetensi (X1) melalui Motivasi (Z) terhadap Kinerja (Y) adalah perkalian antara nilai beta Kompetensi (X1) terhadap Motivasi (Z) dengan nilai beta Motivasi (Z) terhadap Kinerja (Y) yaitu : 
$0,909 \times 0,580=0,527$. Maka Pengaruh total yang diberikan Kompetensi (X1) terhadap Kinerja (Y) adalah Pengaruh langsung ditambah dengan pengaruh tidak langsung yaitu : $0,285+0,527$. Berdasarkan hasil perhitungan bahwa nilai pengaruh langsung sebesar 0,285 dan pengaruh tidak langsung sebesar 0,527 yang berarti nilai pengaruh tidak langsung lebih besar dibandingkan dengan nilai pengaruh langsung, hasil ini menunjukan bahwa secara tidak langsung Kompetensi melalui Motivasi mempunyai pengaruh Signifikan terhadap Kinerja Pegawai di Dinas Pendidikan dan Kebudayaan Kota Lubuklinggau.

\section{Pengaruh Lingkungan Kerja terhadap Kinerja Pegawai melalui Motivasi sebagai Variabel Intervening}

Berdasarkan hasil Koefisien jalur model II diperoleh nilai Koefisien determinasi sebesar $\mathrm{R}^{2}=0,840$ hal ini menunjukan Variabel Lingkungan Kerja $\left(\mathrm{X}_{2}\right)$ terhadap Kinerja (Y) melalui Motivasi sebagai variabel Intervening sebesar 0,840 atau $84 \%$ dan setelah disesuaikan nilai sebesar 16\% dipengaruhi oleh Variabel lain yang tidak dimasukan dalam peneliti ini.

Berdasarkan dari hasil perhitungan nilai beta diketahui pengaruh langsung yang diberikan Lingkungan Kerja (X2) terhadap Kinerja (Y) sebesar 0,619. Sedangkan pengaruh tidak langsung Lingkungan Kerja (X2) melalui Motivasi (Z) terhadap Kinerja (Y) adalah perkalian antara nilai beta Lingkungan Kerja (X2) terhadap Motivasi (Z) dengan nilai beta Motivasi (Z) terhadap Kinerja (Y) yaitu : 0,802 x 0,839 $=0,673$. Maka pengaruh total yang diberikan Lingkungan Kerja (X2) terhadap Kinerja (Y) adalah pengaruh langsung ditambah dengan pengaruh tidak langsung yaitu : 0,619+ 0,673 . Berdasarkan hasil perhitungan bahwa nilai Pengaruh langsung sebesar 0,619 dan pengaruh tidak langsung sebesar 0,673 yang berarti nilai pengaruh tidak langsung lebih besar dibandingkan dengan nilai pengaruh langsung, hasil ini menunjukan bahwa secara tidak langsung Lingkungan Kerja melalui Motivasi mempunyai Pengaruh Signifikan terhadap kinerja pegawai Dinas Pendidikan dan Kebudayaan Kota Lubuklinggau

\section{KESIMPULAN}

Berdasarkan hasil Penelitian dan pembahasan dapat disimpulkan sebagai berikut :

1. Berdasarkan Variabel Kompetensi nilai uji $\mathrm{t}$ dapat dijelaskan bahwa $\mathrm{t}$ hitung menghasilkan Koefisien sebesar 16,347.dengan hal ini dapat dikatakan bahwa Kompetensi memiliki pengaruh yang Signifikan terhadap Motivasi karena $t_{\text {hitung }}(16,347)>t_{\text {tabel }}(1,672)$.

2. Berdasarkan Variabel Lingkungan kerja nilai uji $t$ dapat menunjukan bahwa $t_{\text {hitung }}$ menghasilkan Koefisien sebesar 10,038. dengan hal ini dapat dikatakan bahwa Lingkungan Kerja memiliki Pengaruh yang Signifikan terhadap Motivasi karena $t_{\text {hitung }}(10,038)>t_{\text {tabel }}(1,672)$.

3. Berdasarkan Variabel Kompetensi nilai uji $\mathrm{t}$ dapat dijelaskan bahwa $\mathrm{t}$ hitung menghasilkan Koefisien sebesar 10,412. dengan hal ini dapat dikatakan bahwa Kompetensi memiliki pengaruh yang Signifikan terhdap Kinerja karena $\mathrm{t}_{\text {hitung }}$ $(10,412)>t_{\text {tabel }}(1,672)$.

4. Berdasarkan Variabel Lingkungan kerja Nilai uji $t$ dapat menunjukan bahwa $t_{\text {hitung }}$ menghasilkan koefisien sebesar 14,897. Dengan hal ini dapat dikatakan bahwa Lingkungan Kerja memiliki Pengaruh yang Signifikan terhadap Kinerja karena t hitung $(14,897)>t_{\text {tabel }}(1,672)$.

5. Berdasarkan Variabel Motivasi Nilai Uji t dapat menunjukan bahwa $t$ hitung menghasilkan koefisien sebesar 11,529. dengan hal ini dapat dikatakan bahwa Motivasi memiliki Pengaruh yang Signifikan terhadap Kinerja karena $t_{\text {hitung }}$ $(11,529)>t_{\text {tabel }}(1,672)$.

6. Berdasarkan dari hasil perhitungan nilai $\mathrm{f}$, diperoleh nilai $\mathrm{f}_{\text {hitung }} 152,197>\mathrm{f}_{\text {tabel }} 3,16$ 
sehingga terdapat pengaruh secara Simultan antara Kompetensi dan Lingkungan Kerja terhadap Kinerja Pegawai di Dinas Pendidikan dan Kebudayaan Kota Lubuklinggau..

7. Berdasarkan hasil Koefisien jalur Model I diperoleh nilai koefisien Determinasi sebesar $\mathrm{R}^{2}=0,718$, hasil perhitungan bahwa nilai pengaruh langsung sebesar 0,285 dan pengaruh tidak langsung sebesar 0,527 yang berarti nilai pengaruh tidak langsung lebih besar dibandingkan dengan nilai pengaruh langsung, hasil ini menunjukan bahwa secara tidak langsung Kompetensi melalui Motivasi mempunyai pengaruh Signifikan terhadap Kinerja Pegawai di Dinas Pendidikan dan Kebudayaan Kota Lubuklinggau

8. Berdasarkan hasil Koefisien jalur model II diperoleh nilai Koefisien Determinasi sebesar $\mathrm{R}^{2}=0,840$, hasil perhitungan bahwa nilai pengaruh langsung sebesar 0,619 dan pengaruh tidak langsung sebesar 0,673 yang berarti nilai pengaruh tidak langsung lebih besar dibandingkan dengan Nilai pengaruh langsung, hasil ini menunjukan bahwa secara tidak langsung Lingkungan Kerjamelalui Motivasi mempunyai Pengaruh Signifikan terhadap Kinerja Pegawai Dinas Pendidikan dan Kebudayaan Kota Lubuklinggau.

\section{SARAN}

Setelah ditarik kesimpulan, peneliti memberikan saran dan semoga dapat memberikan manfaat bagi Pegawai Dinas Pendidikan dan Kebudayaan Kota Lubuklinggau sebagai berikut :

1. Agar Pegawai dapat bekerja secara maksimal untuk meningkatkan kualitas maupun kuantitas, maka lingkungan kerja perlu di perhatikan sehingga kompetensi yang dimiliki dapat terus ditingkatkan lebih baik lagi.

2. Motivasi yang diterapkan saat ini kepada Pegawai Dinas Pendidikan dan Kebudayaan Kota Lubuklinggau, hendaknya tetap dipertahankan, bila perlu ditingkatkan lagi agar para pegawai semakin giat lagi untuk bekerja dengan lebih maksimal.

3. Kinerja akan maksimal apabila didukung oleh kebijakan-kebijakan yang diberikan pimpinan sebagai penghargaan atau rasa peduli perusahaan terhadap hasil kerja pegawai.

\section{DAFTAR PUSTAKA}

[1] Kasmir, Manajemen Sumber Daya Manusia. Jakarta, 2016.

[2] Wibowo, Manajemen Kinerja. Jakarta, 2016.

[3] Umar Nimran dan Amirullah, Manajemen Sumber Daya Manusia \& Perilaku Organisasi. Malang, 2015.

[4] Bintoro dan Daryanto, Manajemen Penilain Kinerja Karyawan. Yogyakarta, 2017.

[5] D. Miftahul Ainun Naim Basori,Wawan Prahiawan, "Pengaruh Kompetensi Karyawan Dan Lingkungan Kerja Terhadap Kinerja Karyawan Melalui Motivasi Kerja Sebagai Variabel Intervening," J. Ris. Bisnis dan Manaj. Tirtayasa, vol. 1(2): hh.1, no. issn 2599-0837, 2017.

[6] Eddy Sutrisno, Manajemen Sumber Daya Manusia. Jakarta, 2015.

[7] Moeheriono, Pengukuran Kinerja Berbasis Kompetensi. Jakarta, 2014.

[8] Sedarmayanti, Tata Kerja dan Produktivitas Kerja. Bandung, 2011.

[9] Nitisemito, Manajemen Personalia. jakarta, 2015. 
[10] Sugiyono, Metode Penelitian Kuantitatif. Bandung: Alfabeta, 2018.

[11] Wiratna Sujarweni, Metodologi Penelitian Bisnis dan Ekonomi. Yogyakarta, 2015.

[12] M. . Ir.Syofian Siregar, Metode Penelitian Kuantitatif Perhitungan Manual \& Spss, Edisi pert. Jakarta: Kencana, 2013.

[13] M. B. . DR. RIDUWAN, Metode \& Teknik Menyusun Proposal Penelitian. Bandung: Alfabeta.

[14] Kasmadi dan Nia Siti Sunariah, Panduan Modern Panduan Kuantitatif. Bandung: Alfabeta, 2014.

[15] P. H. I. Ghozali, Aplikasi analisis multivariate dengan program IBM SPSS 25. semarang, 2018. 